\title{
Design, Synthesis and Biological Evaluation of Semicarbazide-Sensitive Amine Oxidase (SSAO) Inhibitors with Anti-inflammatory Activity
}

Eric Y. Wang*, Hongfeng Gao, Luisa Salter-Cid, Jun Zhang, Li Huang, Erika M. Podar, Andrew Miller, Jingjing Zhao, Anne O’Rourke, and Matthew D Linnik

La Jolla Pharmaceutical Company, 6455 Nancy Ridge Drive, San Diego, CA 92121, USA

\section{Summary of Elemental Analysis}

\begin{tabular}{|c|c|c|c|c|}
\hline Compound \# & Formula & & Calculate & Found \\
\hline \multirow[t]{3}{*}{$4 a$} & $\mathrm{C}_{9} \mathrm{H}_{12} \mathrm{~N}_{2} \cdot \mathrm{HCl}$ & $\mathrm{C}$ & 58.54 & 58.33 \\
\hline & & $\mathrm{H}$ & 7.10 & 7.09 \\
\hline & & $\mathrm{N}$ & 15.17 & 15.22 \\
\hline \multirow[t]{3}{*}{$4 b$} & $\mathrm{C}_{9} \mathrm{H}_{11} \mathrm{ClN}_{2} \cdot \mathrm{HCl}$ & $\mathrm{C}$ & 49.33 & 449.39 \\
\hline & & $\mathrm{H}$ & 5.52 & 5.18 \\
\hline & & $\mathrm{N}$ & 12.79 & 12.48 \\
\hline \multirow[t]{3}{*}{$4 c$} & $\mathrm{C}_{9} \mathrm{H}_{11} \mathrm{FN}_{2} \cdot \mathrm{HCl}$ & $\mathrm{C}$ & 53.34 & 53.26 \\
\hline & & $\mathrm{H}$ & 5.97 & 5.62 \\
\hline & & $\mathrm{N}$ & 13.82 & 13.92 \\
\hline \multirow[t]{3}{*}{$4 d$} & $\mathrm{C}_{10} \mathrm{H}_{14} \mathrm{~N}_{2} \cdot \mathrm{HCl}$ & $\mathrm{C}$ & 60.45 & 60.15 \\
\hline & & $\mathrm{H}$ & 7.61 & 7.23 \\
\hline & & $\mathrm{N}$ & 14.10 & 14.24 \\
\hline
\end{tabular}




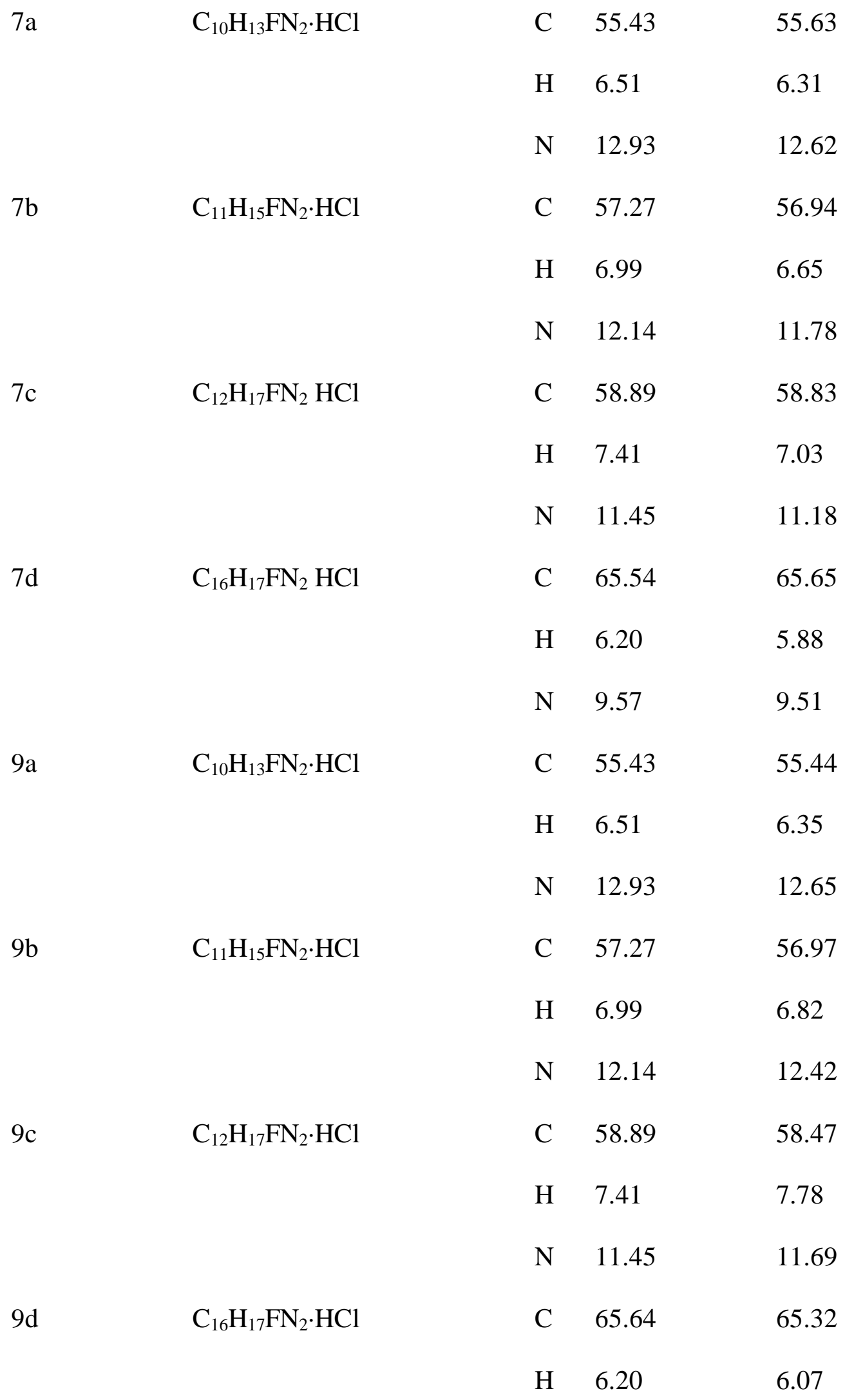


C $\quad 53.34$

53.40

H 5.97

6.32

N 13.82

14.01 